\title{
Benefits \\ of three-dimensional imaging
}

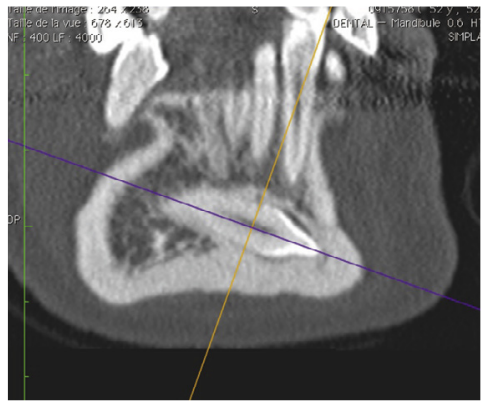

\section{Olivier SOREL, Annie OLLIVIER, Marie-Charlotte MANO}

\section{ABSTRACT}

Three dimensional images derived from X-Rays, scans or Digital Cone Beam Computed Tomography (CBCT) are components of supplementary diagnostic procedures. Using them, practitioners can visualize the anatomic relationships of teeth with each other and with adjacent structures and can discern the presence or absence of root resorption.

These radiographic films can assist in the diagnostic evaluation of impacted, transposed, or duplicated teeth or those situated on the edges of facial clefts. They are indispensable in helping diagnosticians to rule out contraindications as they establish treatment plans and continue to be useful as guides when mechano- therapy starts.

Recently, CBCT has become accessible for use in dental offices even though it has been an expensive and bulky instrument with a relatively high radiation output. Today, with a more acceptable radiation dosage, it is well accepted as an alternative diagnostic procedure in the field of oro-facial implants, but overall, it cannot yet be considered as a technique that should be systematically employed in every supplementary examination.

\section{KEYWORDS}

Cone Beam Computed Tomography

Computerized Tomography

Orthodontics

Radiographic exposure guidelines

Embedded Canines. 


\section{1 - INTRODUCTION}

The canines, particularly the maxillary ones, are the teeth which are most frequently over-retained or impacted. The objective of this study is to demonstrate the benefits of modern threedimensional imaging in evaluating the spatial position of these teeth and their relationship with neighbouring structures. This evaluation is particularly important in making decisions for treatment. Uncovering and moving an impacted tooth into its proper position in the arch may be impossible or particularly risky. Because of its importance as a strongly rooted and powerful tooth, dentists are justifiably reluctant not to make the effort to bring it into place, so the decision to extract it or leave it untouched in its original position should only be made after an exhaustive and well-reasoned diagnosis. If a plan to uncover and move it ${ }^{17}$ is indicated, three-dimensional imaging can be a most helpful tool to, first, help oral surgeons choose their approach and, next, for orthodontists to determine the direction in which to apply traction. We discuss this subject from a clinical not an exhaustive academic point of view, pointing out in addition other indications $^{1}$ for this type of imaging. In conclusion, we discuss the benefits of cone-beam imaging compared with the classic scanner.

\section{2 - INDICATIONS AND BENEFITS OF IMAGING IN LOCATING EMBEDDED TEETH}

Today dentists extract canine teeth only as a last resort only when no other treatment is possible. There was a time when the "saber" tooth was often removed for cosmetic reasons and even if its importance as a key to a balanced occlusion is a matter of dispute, and even if the importance of the canines in occlusal balance is questionable; the cessation of their promiscuous extraction marks a forward step for dentistry.

Sometimes the problems posed to the movement of impacted cuspids into place are almost insurmountable. So in making the decision to elect such a course of treatment dentists must always weigh the risk/benefit ratio against the therapeutic benefits that might be obtained. To evaluate those therapeutic risks the practitioner must determine the precise location of the impacted tooth, its relationship with its anatomical environment, and the path it must take to move into position.

How can practitioners view the invisible? Since Rontgen, X-rays have given them a means to observe most of the internal structures of the body. Conventional imaging by projection provides excellent service in medicine and odontology. This type of examination has become a routine component of our clinical practice. Orthodontists use it, for example, to take diagnostic cephalometric films. But this technique provides information that is incomplete and sometimes inaccurate in locating impacted teeeth7, 9, 13 .

From profile and frontal cephalometric films, the examiner can gain a rough idea of an impacted tooth's position that might be confirmed by palpation of 
a bulge. In such cases it is not necessary for the patient to endure further costly and irradiating supplementary radiographic imaging 20 .

Clinical examination by direct palpation is a reliable way of evaluating position ${ }^{3}$ when it is positive.

The treating dentist can use the panoramic X-Ray to obtain an over-all but not anatomically precise view of the dentition. The curving movement of the cone head taking a panoramic film makes the perceived axial inclination of teeth, particularly the canines, unreliable. When a tooth is not located in the thicker portion of a sector, its image is blurred and it is impossible to determine accurately whether the tooth is in front of or behind the plane of the section (fig. 1). A canine that is thought to be missing may go unperceived on first inspection. And even if

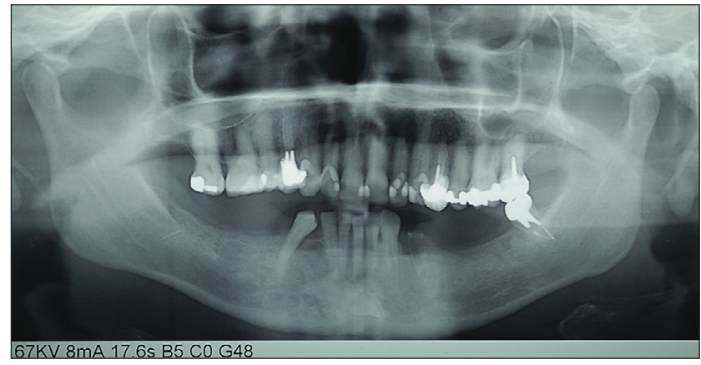

Figure 1

Panoramique dentaire montrant un nombre important de dents absentes. Au premier examen l'image floue de la canine dans la symphyse peut passer inaperçue.

it is remarked, its blurred image cannot give an accurate idea of its location. Unless a clinical examination provides the required information, further radiological investigation is essential. The examination of choice is three-dimensional scanning or for defining the indications and

\begin{tabular}{|l|l|l|l|}
\hline & Panoramic & X-ray scan & Cone beam \\
\hline Chronology & 1950 & 1972 & 1988 \\
\hline Technique/definition & $\begin{array}{l}\text { Analogical sagittal and } \\
\text { frontal sections }\end{array}$ & $\begin{array}{l}\text { The X-ray beam is collimated } \\
\text { to the thickness of the sec- } \\
\text { tion and recorded on emer- } \\
\text { gence by a ring of detectors }\end{array}$ & $\begin{array}{l}\text { The pulsed, open, conical } \\
\text { section } \text {-ray beam makes } \\
\text { dental-maxillary structures }\end{array}$ \\
\hline $\begin{array}{l}\text { Protocol, } \\
\text { patient comfort }\end{array}$ & Standing, seated & Supine, immobile & Standing, seated \\
\hline $\begin{array}{l}\text { Dosimetric estimate } \\
\text { in } \mu \text { Sv }\end{array}$ & 6 to $15 \mu S v$ & 50 to $120 \mu$ Sv & 10 to $65 \mu S v$ \\
\hline $\begin{array}{l}\text { Dosimetric estimate } \\
\text { in equivalent days of } \\
\text { natural irradiation }\end{array}$ & 1 to 3 days & 8 to 20 days & 2 to 11 days \\
\hline Cost & Low & High & Intermediate \\
\hline
\end{tabular}

Table 1

Summary of the different imagers (Panoramic, X-ray scanner and Cone beam). The doses given depend on the machines and the accuracy of the examination, i.e. the thickness of the section for the scanner and size of voxel for the cone beam. A wide field cone beam examination with high definition may involve more radiation than a simple scan. 
contraindications for uncovering an impacted tooth, the surgical approach, and the orthodontic mechanics to be implemented, notably the orientation of traction.

\section{2 - 1 - Contraindications for uncovering an impacted tooth}

In the previous case (fig. 1), the implantologist prescribed a scan to display the relationship of an ectopic canine with its environment accurately through coronal, axial and frontal sections (fig. 2 a to d). This examination established a contraindication for uncovering it, which in this case would have posed more risks than benefits for two reasons: firstly, this tooth is located very far from its ideal position and secondly the path it would need to take to join the arch would involve an L-shaped route to avoid the incisor apices. Initially, the orthodontist would have had to move it horizontally before changing its path to a vertical vector. Such an intricate maneuver is almost impossible to achieve and, accordingly, the prognosis would have been highly unfavourable.

An extremely ectopic position of an impacted tooth ${ }^{12}$ can, in itself, sometimes be a contra-indication for orthodontically moving it into place.
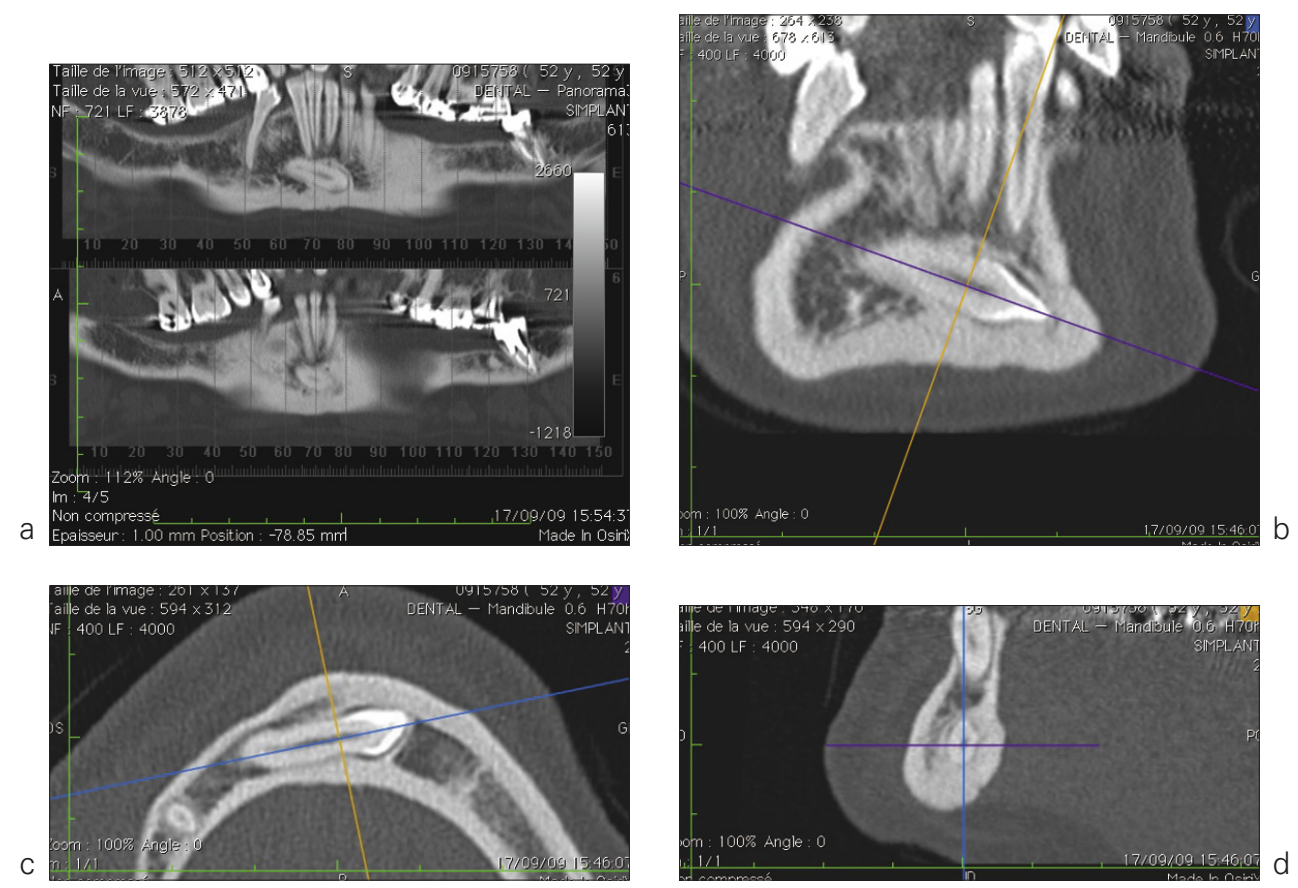

Figures 2 a to $d$

With Images taken from an X-ray scanner examiners can make very different types of reconstruction such as images like this dental panoramic view (a) which looks like a standard panoramic X-ray except that the operator selected the plane of the section. Other images, frontal sections (b), horizontal sections (c) and axial sections (d) were also constructed that helped to perfect the picture of the impacted tooth and its anatomical environment. 
In this case, transplantation, depending upon the suitability of the location of the tooth as well as the site into which it will be placed, may be an acceptable alternative treatment. The prognosis for transplantation depends on how effectively it can be removed from its original site, with excellent preservation of its periodontal membrane, the tissue that will have the potential to re-establish a bond with enveloping alveolar bone. But the anatomical situation of the impacted tooth could be such that removing it would inevitably damage neighbouring structures.

Finally, the practitioner may decide that doing nothing at all would be the best treatment, providing leaving the impacted tooth in place would not pose any risks of infection or to planned orthodontic or implant therapy. This was the decision we made for the patient depicted in (fig. 2 a to d) where we had, in a pre-implant scanning film found, to our surprise, an ectopically placed canine.

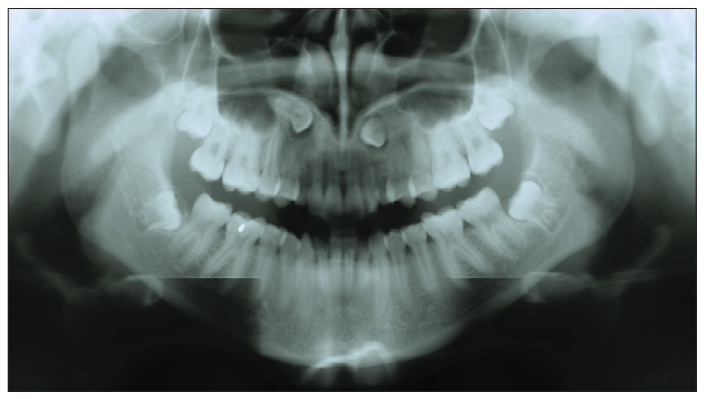

Figure 3

This panoramic film shows blurred images of two ectopically placed canines but it gives only a scanty idea of the anatomical relationships between the teeth and the structures surrounding them.
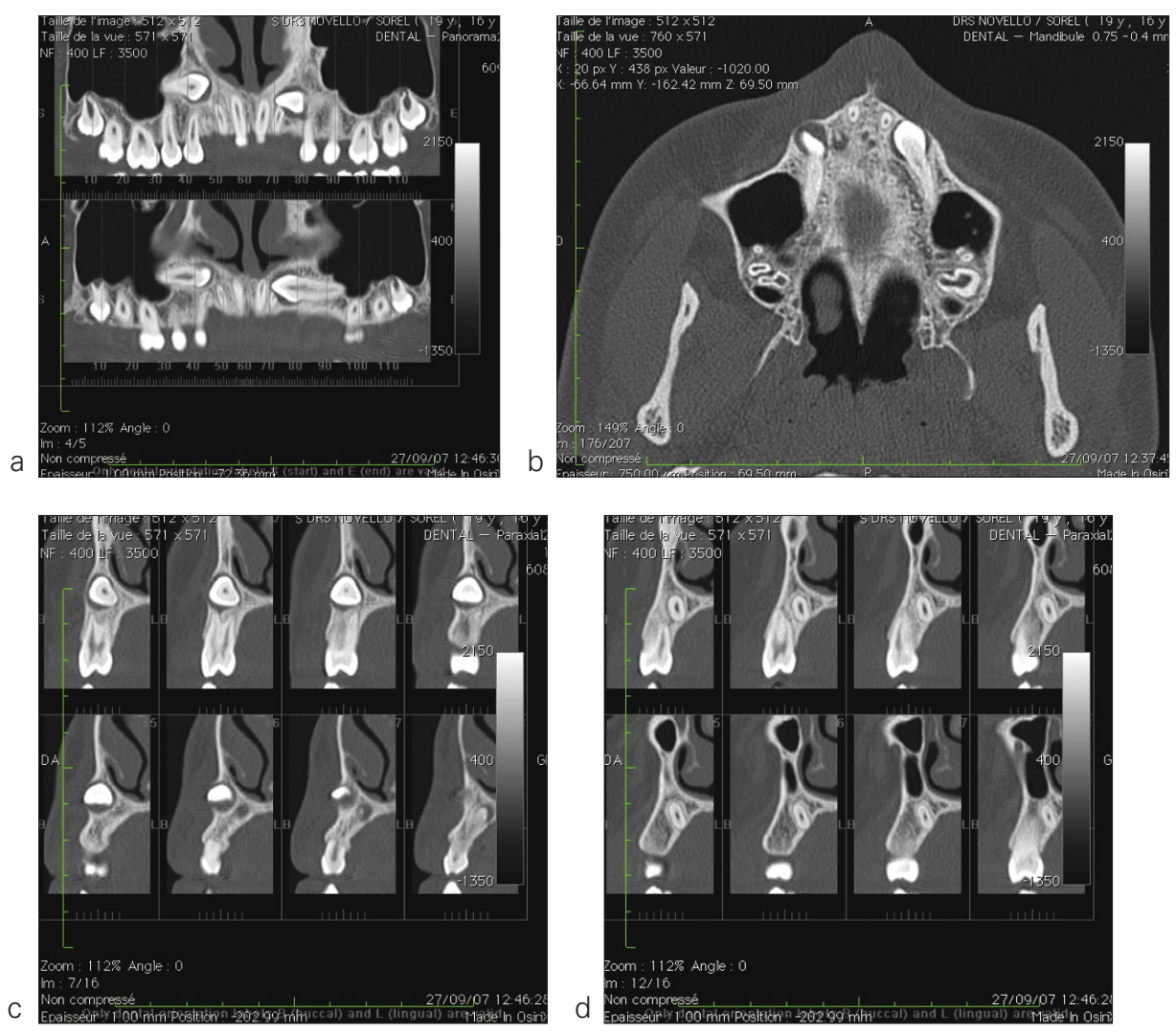

Figures 4 a to $d$ Images taken from an $X$-ray scanner. In the panoramic X-ray (a), the images of canines are imprecise and incomplete: their axes diverge from the plane of the section making them difficult to see. In the horizontal section (b) they can be seen in almost complete totality, which indicates that they are in a horizontal position. The axial sections (c) and (d) provide accurate views of the canines and their anatomical environment. In the sections (c) the apices of the premolars overlap the upper right canine, which make repositioning it orthodontically impossible. Although the impacted upper left canine, still clearly horizontal, can be seen to be in a more palatal position so that its orthodontic correction may be feasible but the difficulties appeared to us to be so great that we recommended extraction. 
Extraction is justified to prevent development of infectious problems like pericoronitis, for the same reasons that extractions of wisdom teeth are sometimes prescribed. Extractions of impacted teeth may also be justified when they might be located in a posture that could interfere with the orthodontic movement of other teeth or cause iatrogenic apical resorption their root apices. Extraction is then the best way of avoiding highly predictable collateral damage.

We made the same decision to extract for another patient, whose two maxillary canines were impacted in a high position. The panoramic X-Ray (fig. 3) showed their position but gave only a vague, blurred image of their anatomical relationship to adjacent teeth, cavities, and bone structures. But with a 3D image that did reveal these details ${ }^{15}$ (fig. 4 a to d), we were able to make a reasoned recommendation for extraction.

In a quite different situation we used a scanner to confirm the impression we gained from the panoramic film that an impacted canine could safely be brought into place. But the scanning views showed (fig. 5 a to f) that because of its unfavourable anatomic relationship with the

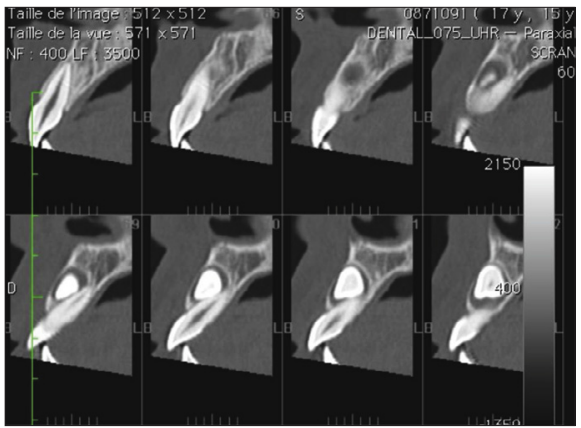

a

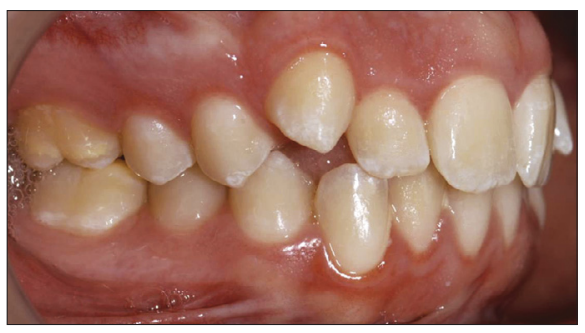

d

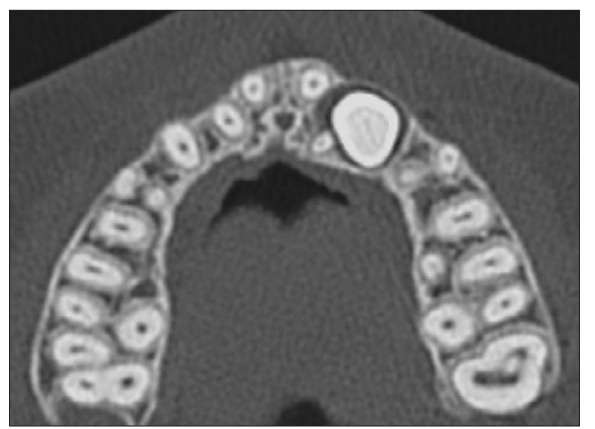

b

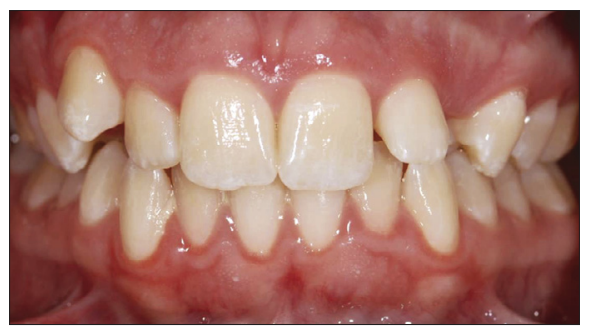

e

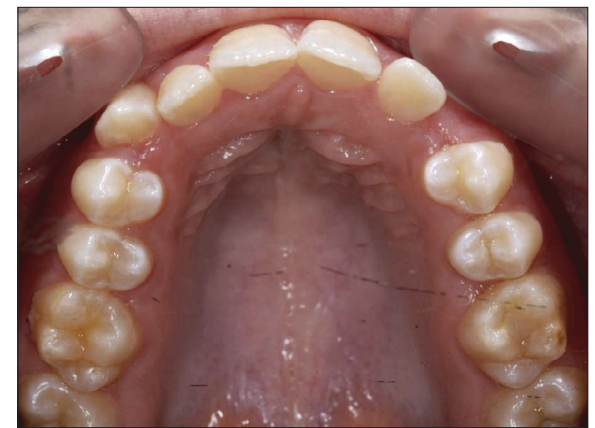

C

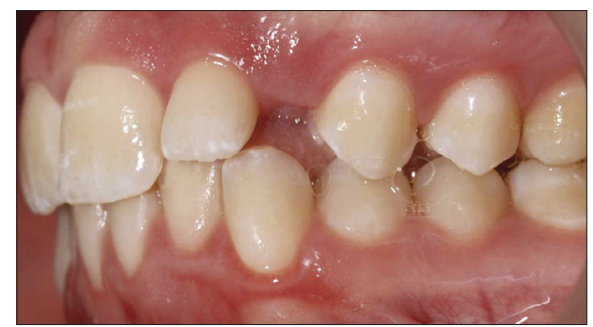

f

Figures 5 a to $f$

Images taken from an X-ray scanner. In the horizontal section (a) above, at the level of the apices, the canine, which has a palatal inclination, seems to be outside the range of the apex of the lateral incisor. But the axial section (b) clearly shows a superposition of the lateral incisor on the canine with slight resorption of the lateral root from contact with the canine's pericoronal sac. It appears that moving the canine would put the lateral at risk. An examination of the occlusal view of the maxillary arch (c) shows that the canine would have to be moved outward and forward, a difficult maneuver, to protect the root of the lateral incisor. The intra-oral photos (d, e and f) show an Angle Class II left hand subdivision with deviation of the maxillary-mandibular midline. An assessment of the risk-benefit ratio led us to extract the impacted tooth. In mechano-therapy, we closed residual space left by the temporary canine which gave room for the buccally blocked-out right canine, and allowed us to correct the center line by mesializing the left premolar-molar sector. 
adjacent lateral incisor orthodontic mechano-therapy would be accompanied by a high risk of iatrogenic damage to the root of the lateral. The risk-benefit ratio appeared to us to be unfavourable and after discussion with the patient, we decided to extract the impacted tooth.

\section{2 - 2 - Indications for uncovering an impacted tooth}

In establishing accurate anatomical relationships between impacted teeth and neighbouring structures we do more than determine the way to approach them surgically. We also establish, by scrupulously examining the X-ray images, sections and reconstitutions, the best path to place it on to avoid obstacles as it moves to its correct position in the arch. When impacted canines lie in buccal positions, they are usually easy to uncover and can be moved into arch with no major technical problems ${ }^{16}$.

However, sometimes 3D imaging is a great help in protecting practitioners from making faulty assessments on the basis of information provided by routine X-rays. The crown of the impacted canine of the young patient

a
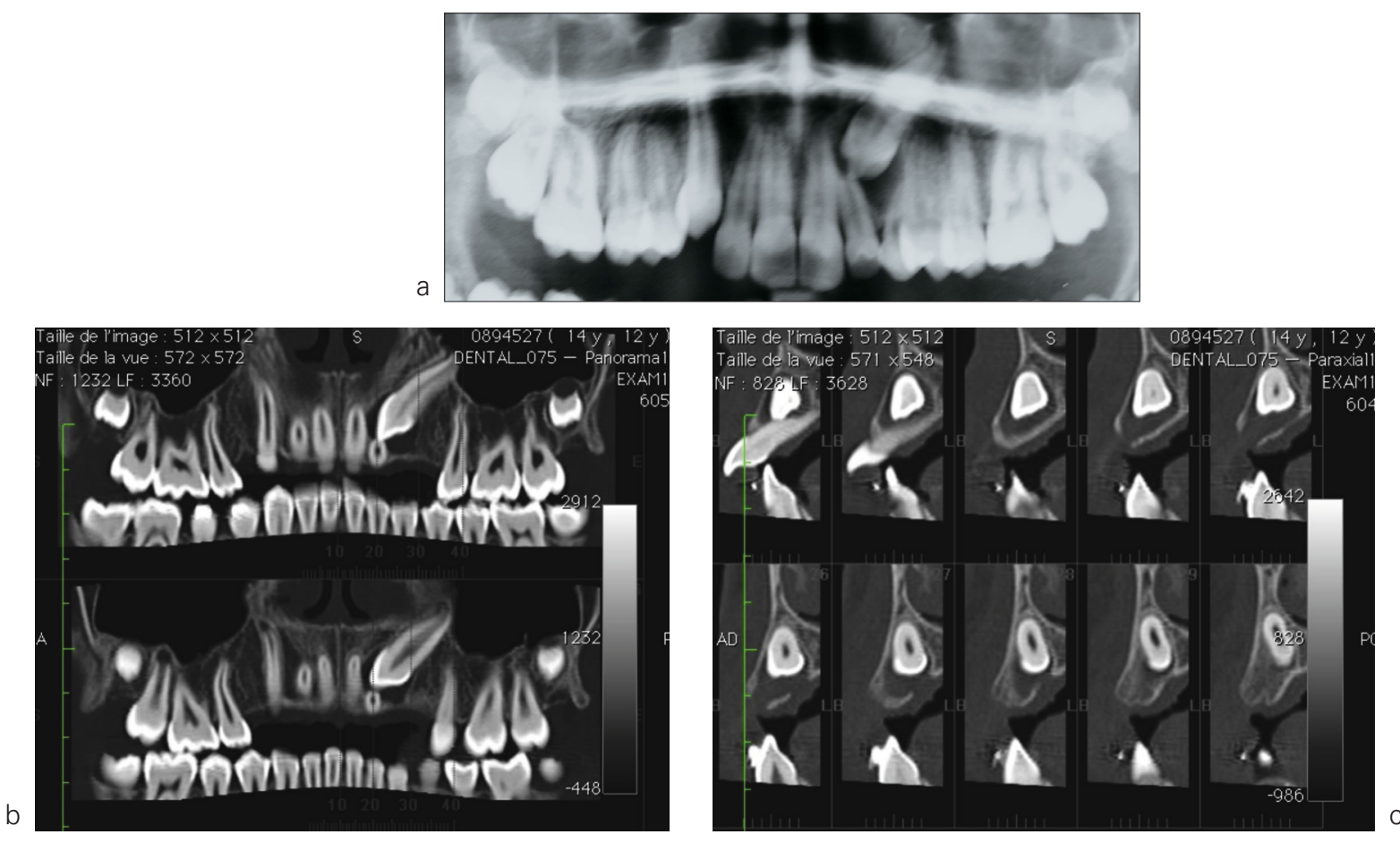

Figures 6 a to $c$

Images taken from an X-ray scanner examination. The dental panoramic view (b) does not give much more information than the dental panoramic view (a). The axial sections (c) show us, as in figure 5, a close connection between the crown of the canine and the root of the lateral incisor (already partially resorbed). The only suitable traction route would be outward and distally in a route that would be just as risky as the one projected for the previous case. But for this patient it was essential to preserve the impacted canine because premolars had already been extracted. We were able to safeguard the endangered lateral by using the fixed anchorage of a mini-screw which allowed us to control the canine movement precisely and avoid all unwanted reciprocal tooth movement. 
depicted in (fig. 6 a to c) lay in a buccal position but its root was more palatal.

In this case an examination of the axial sections provided information on the impacted canine's relationship with its anatomical environment. It suggested a buccal surgical approach and a high horizontal distal route for moving it into place. We monitored the "tunnel" path through which we led the impacted tooth with periapical radiographs (fig. 7 a to e).

After viewing only a panoramic film we fell into the trap of approached the tooth surgically from the palate, an attempt which failed. But with 3D imaging we can avoid such pitfalls and make accurate treatment plans for both surgical and orthodontic procedures. A 3D examination ${ }^{19}$ of another case in which the canine was impacted in a "classical" palatal position (fig. 8 a to g) did not appear to be essential unless we would want to resolve doubts about surgical approach and path of traction. We chose, in this case, a digital cone beam computed tomographic examination that provided easy access and significantly less irradiation at a lower cost. After palpation of a palatal bulge, there was no doubt that a palatal approach to uncovering this impacted tooth was indicated. The sectional views enabled us to avoid the mistake of

a
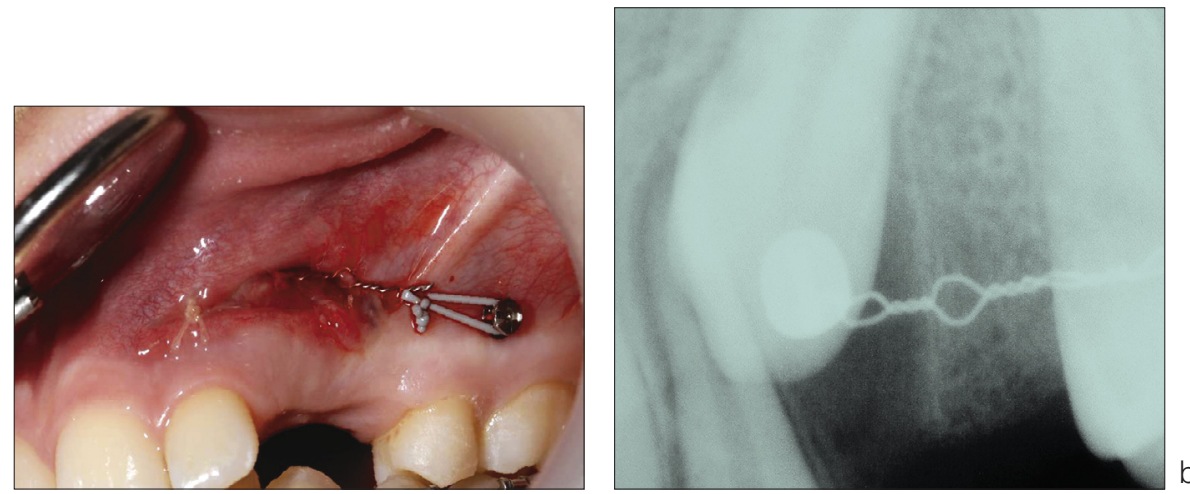

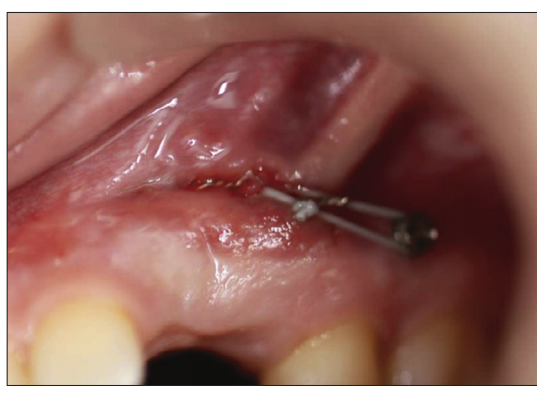

C

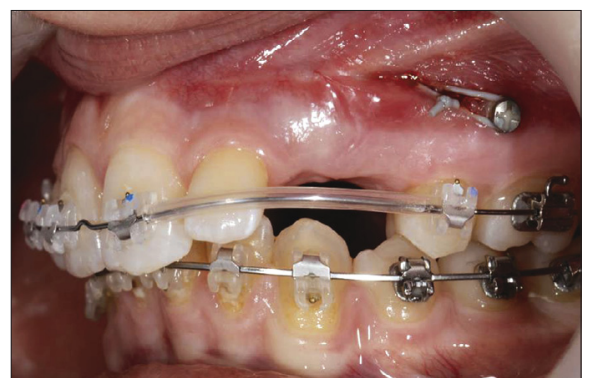

d

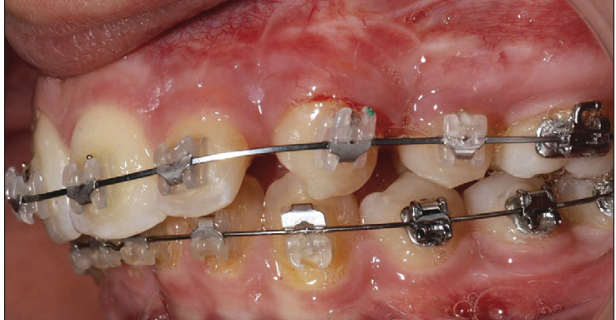

Figures 7 a to e

We monitored the "tunnel" pathway with periapical radiographs (b). We initially applied a horizontal, distal, and outward vector of force $(a, c, d)$. Then, when it was cleared from the root of the lateral incisor, we pulled it down to its final position (e). We did not prescribe a further 3D examination because it would have been of no benefit to the patient. 
pulling the tooth toward its ultimate site in the arch because that route would have damaged the lateral root (fig. 8 a). With the aid of a fixed anchorage palatal mini-screw we were able to insure that the canine was not ankylosed, keep it on a safe pathway, use a non-complicate appliance set-up, and avoid all unwanted reciprocal tooth movements. Only later in treatment did we install a fullbanded appliance set-up.

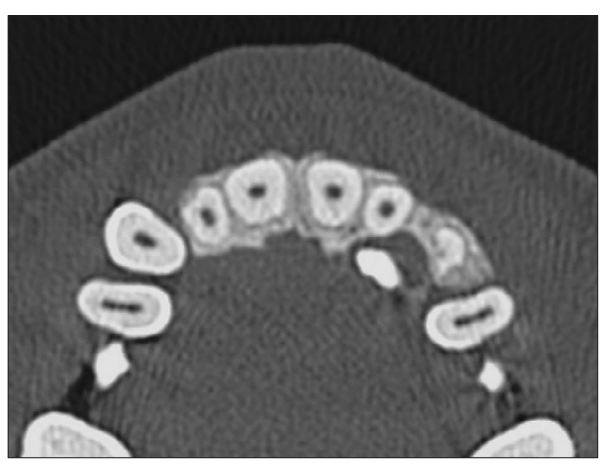

a

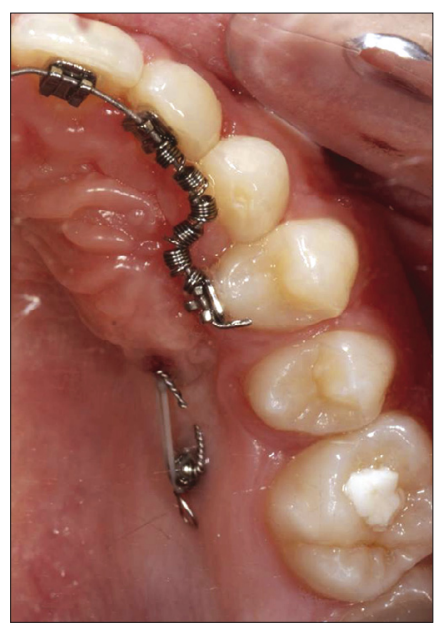

d

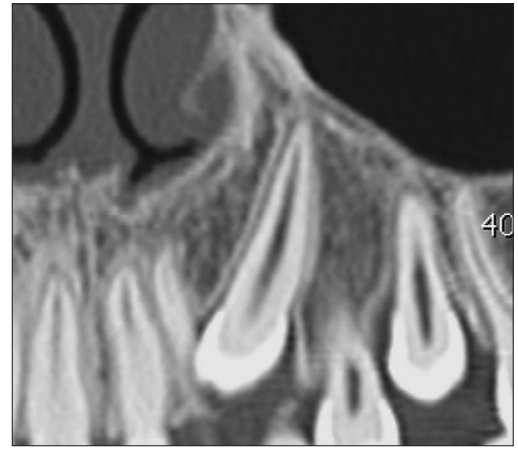

b

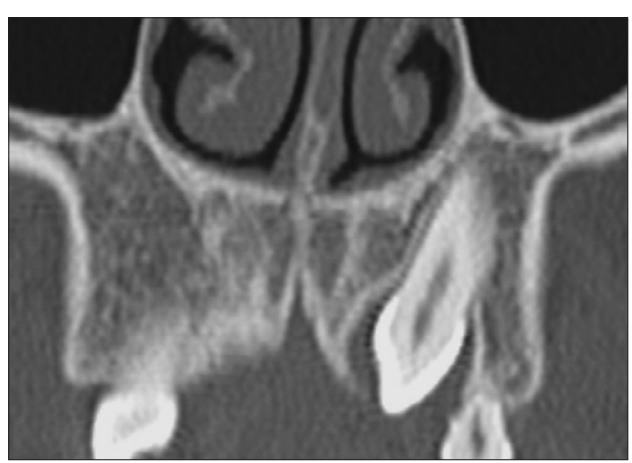

C

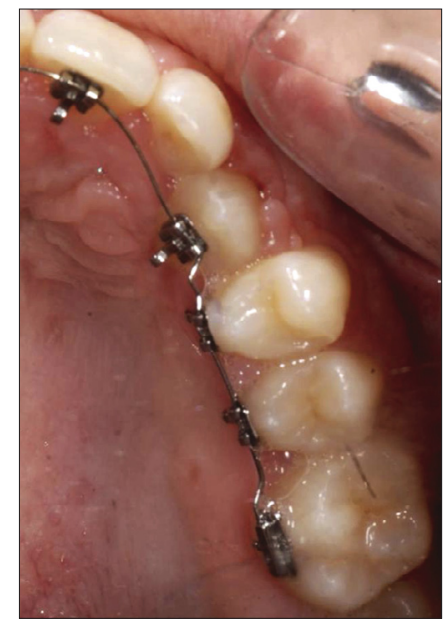

e

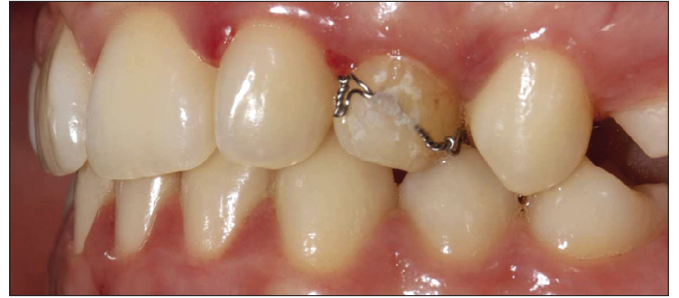

f

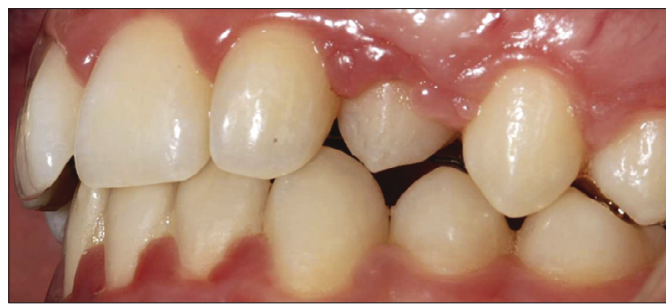

g

Figures 8 a to $g$

For this impacted canine lying in a "classical" palatal position, we chose digital cone beam computed tomography to determine the surgical approach and the best path of traction $(a, b, c)$. We used a palatal mini-screw (d to obtain fixed anchorage that allowed us to move the tooth with a stripped-down appliance, no un-wanted side effects, precisely controlled direction of force and assurance it was not ankylosed before extracting the temporary canine which we kept in place to performs an aesthetic role as long as possible (f). Later, we moved the canine, which had been directed horizontally distally, downward into place and (e) extracted the temporary canine (g). 


\section{3 - OTHER INDICATIONS}

Three-dimensional scanning or digital cone beam computed tomography 10,18 is also indicated for many other cases, either as a diagnostic tool or to elucidate specific atypical anatomical situations such as transpositions and to assist practitioners in making therapeutic decisions.

\section{3 - 1 - Usefulness in diagnosis}

In cases of narrow maxillary arches, for example, it is often difficult to determine what part is played by a problem of basic bone insufficiency and what contribution is made by a narrow dento-alveolar arch. Orthodontists will want to make therapeutic choices that will have no deleterious iatrogenic effects. For the intense debates orthodontists have with themselves and with their colleagues about successful expansion therapy, 3D imaging provides useful information on a number of points, both before and during treatment 11,21 .

Three-dimensional investigation using digital cone beam computer tomography provides worthwhile diagnostic data about teeth and their anatomical relationships with alveolar bone at an irradiation cost to the patient far less than that demanded by a scanner, the equivalent of 2 to 11 days of natural irradiation compared to 8 to 20 .

The initial examination of a patient displaying transverse maxillary insufficiency depicted in fig. 9a to k shows:

- in frontal sections, molar axial inclinations that are quite vertical premolars that are inclined palatally;

- natural fenestrations especially in the premolars regions as seen in frontal and horizontal sections.
The lack of image of the alveolar bone means that it is not dense enough to make an appearance on the X-ray film. Surgeons often report fenestrations in this type of case when orthodontists expand the maxilla;

- a non-calcified inter-maxillary suture.

By providing a view of the weakness of the alveolar rampart, this examination influences the choice of treatment to expand the maxilla thus reducing the burden buccal alveolar bone would have to bear.

After completion of expansion therapy, the 3D examination again provided a wealth of information:

- the frontal sections show that the axial inclination of the molars remains upright, allowing them to serve as stress-breaking supports and that the premolars are now leaning more buccally than lingually;

- the fenestrations persist but do not seem to have worsened. On the 3D surface reconstruction (fig. 9 k) we have images showing major improvement in the osseous support for all the buccal teeth except the upper right second bicuspid. But this view of 15 is not confirmed in the frontal sections; where, on the other hand, 14 seems to be lacking alveolar bone support. The image provided by the horizontal section shows the roots in the alveolar bone more accurately, recording the positions of their roots outside the cortical area but with no great change from the initial situation; 

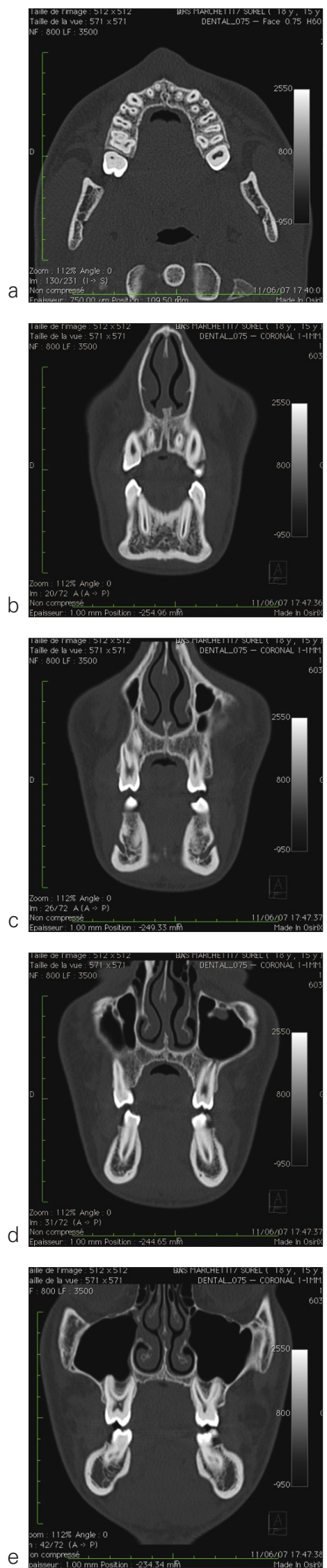
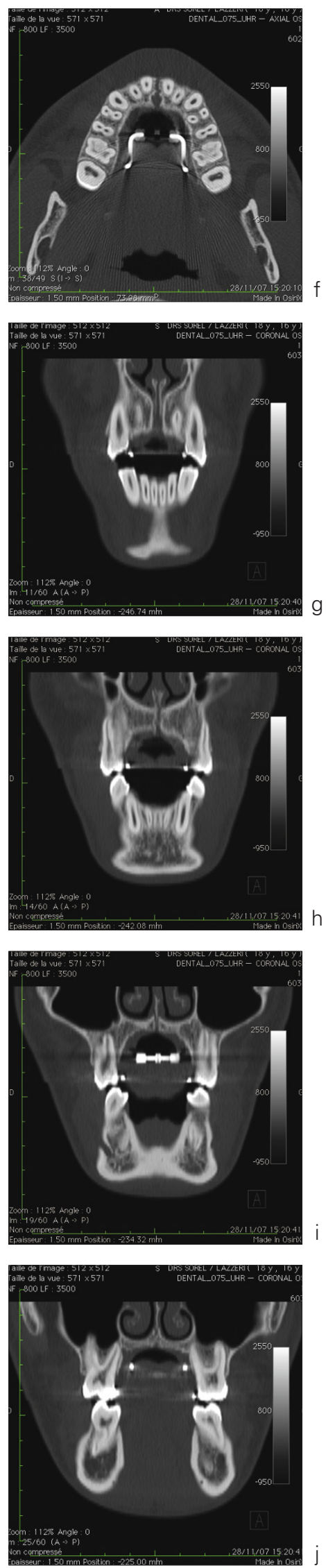

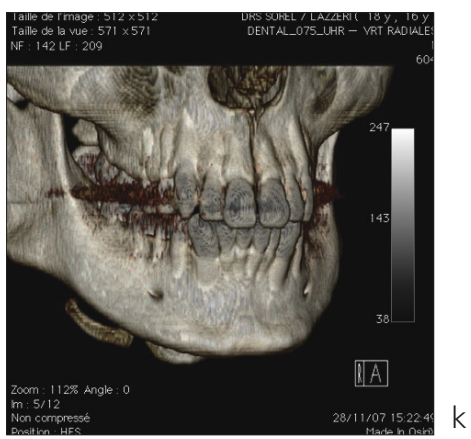

Figures 9 a to $k$

The frontal sections $(b, c, d, e)$ show upright molars and palatally inclined premolars. The inter-maxillary suture is not calcified (a). By providing a view of the weakness of the alveolar rampart, this examination indicates that palatal expansion would fulfill treatment objectives. After expansion treatment, a 3D examination shows in frontal sections that the molar axes have remained vertical and still serve as stressbreaking supports and that the premolars have been uprighted $(g, h, i, j)$. The fenestrations persist but do not seem to have worsened. The 3D surface reconstruction ( $k$ ) images show major root relief. The horizontal section shows the relationship of roots with alveolar bone more accurately and their positions outside the cortical bone areal but with no great change from the initial situation (f). 
- the inter-maxillary suture is clearly open in the anterior zone.

With this kind of imaging, practitioners can gain an accurate visualization of the effects of treatment and make the kind of pertinent and critical analyses that are impossible to form solely on the basis of unreliable, subjective clinical impressions.

\section{3 - 2 - Usefulness for cases of facial clefts and twinned teeth}

Labio-maxillary clefts are often accompanied by impacted or overretained teeth because the cleft in itself is an obstacle to natural eruption of the canines. Bone grafts can solve this problem.

Orthodontists often fail to assess these situations accurately when the exuberant tissue caused by the scars of healing makes it difficult to distinguish supernumerary teeth from permanent teeth erupting normally. A panoramic film may add to the confusion with its often misleading and partial depiction of multiple more or less normal tooth buds in ectopic positions. 3D imaging provides an accurate view of all the teeth and their crowns and roots (fig. 10 a to f) thus enabling the orthodontist to make a reasoned judgment on which teeth to extract.

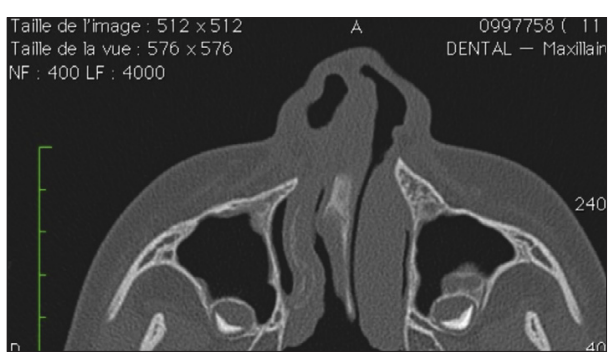

a

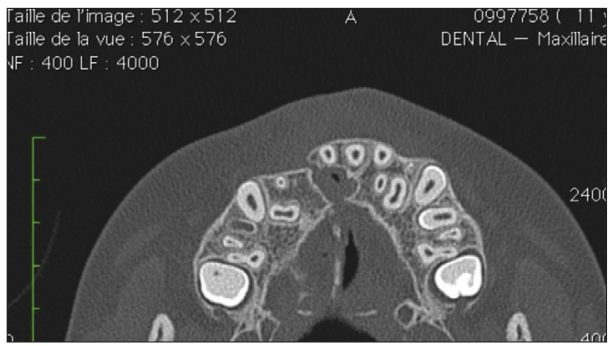

C

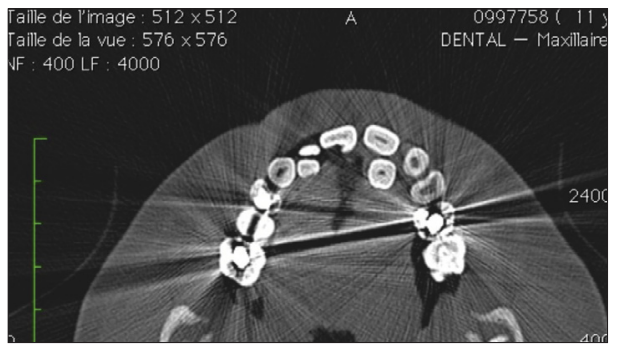

e

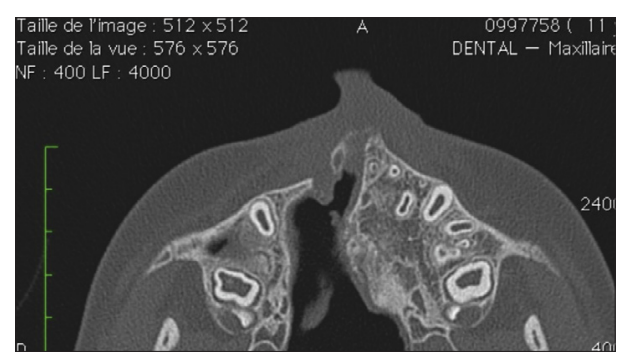

b

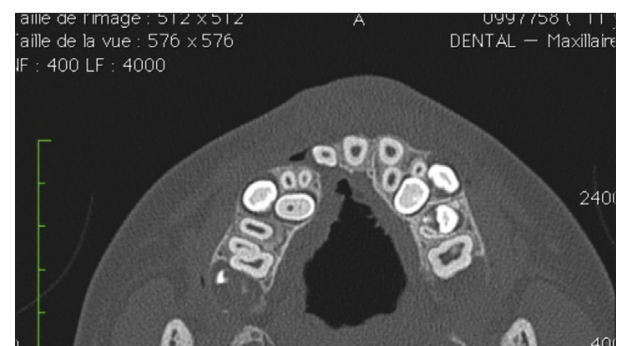

d

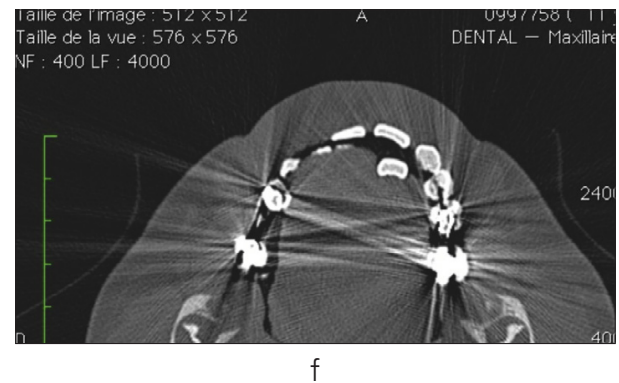

Figures 10 a to $f$

The examiner cannot get an accurate view of the exact position of the teeth or their anatomy from a panoramic $X$-ray film. But 3D imaging does provide a clear picture of all the teeth, their crowns and roots. From it, the orthodontist can evaluate all the available see anatomic structures and relationships of teeth to them. It is hard to show, with a few pictures on a page, how valuable these types of examination can be. But these six sections $(a, b$, $c, d, e, f)$, which illustrate a case of a right unilateral cleft, give some idea of their clarity. In them, we can follow this cleft from the highest section (a) to the lowest (f). Similarly, we can readily identify the position and size and shape of impacted teeth as well as assess the size of their roots and their relationships to neighbouring structures, including the cleft. 
A similar, but much more benign and rather rare problem of a twinned lateral incisor is depicted in (fig. 11 a to f). The young patient had two upper right temporary lateral incisors. After they were shed naturally, no permanent successors appeared to replace them. The dental panoramic film showed twinned unerupted permanent lateral incisors but did not give enough information to help decide which one to extract. The 3D image did give a somewhat clearer picture of two well-formed teeth, with roots close together. The more distal one is slightly bigger. In this case, their morphology is not the criterion of choice. The most mesial position is the better and also the simpler to extract. The more distal may suffer from the proximity of the canine and could be resorbed at the contact point. The image is not clear on this point. Neither is it possible to view the colour of the teeth. In this

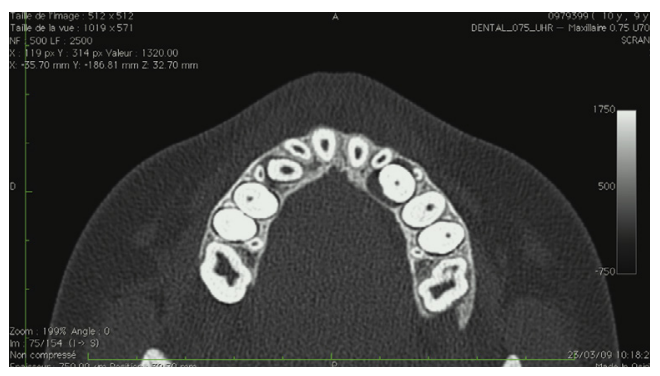

a

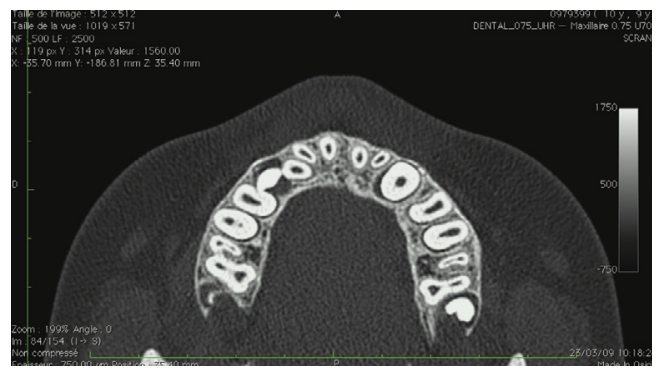

b

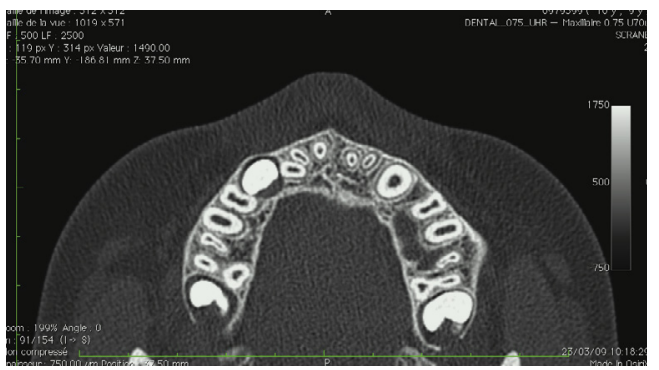

C

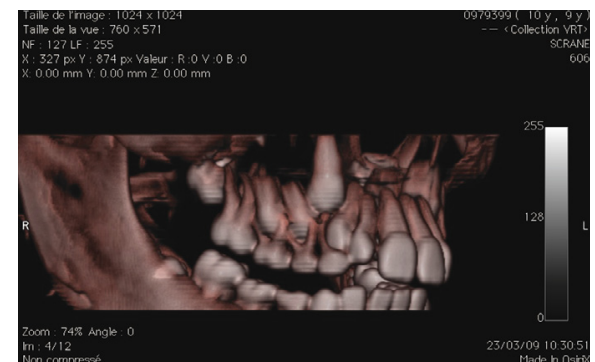

d

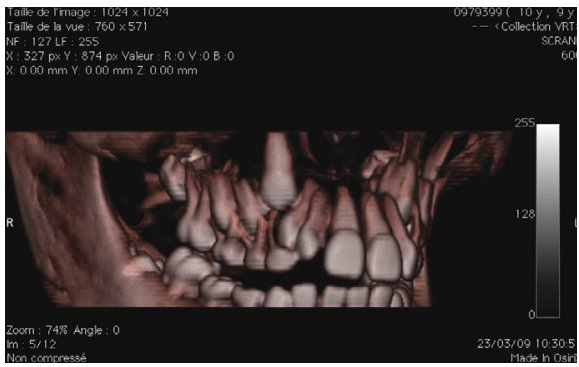

e

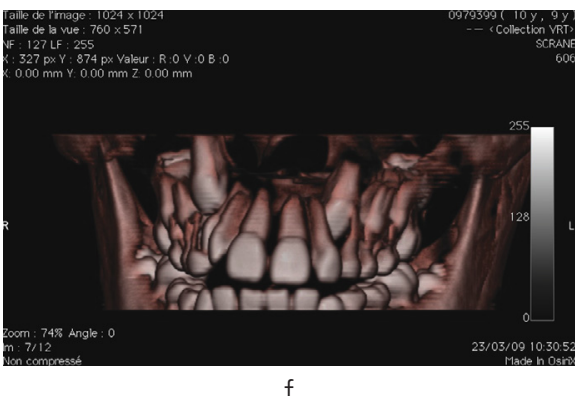

Figures 11 a to $f$

$3 D$ imaging was used to solve the problem of choosing which tooth to extract in this case of double lateral incisor. The dental panorama shows the doubling but is not accurate enough to orient the choice of extraction. The 3D image shows two well-formed teeth, with roots very close together. 
case, extracting one of the two teeth promotes eruption of the other; doing nothing compromises the more distal incisor. We had no clear choice and since we had to make some kind of decision, we asked the oral surgeon to extract the more distal tooth, if, and only if he was sure that the more mesial tooth would not be damaged in the process. If he was not sure, in view of the over-all surgical difficulties involved, extraction of the more mesial tooth seemed to us to be preferable.

\section{3 - 3 - Usefulness in cases of transpositionde transpositions}

The case of dental transposition 8 deserves to be at least to be men- tioned here. But L. Delsol will present it in greater detail in the next issue. The difficulty in treating transpositions lies mainly in the anatomical relationships these teeth have with other structures and dental units. 3D imaging becomes an invaluable tool in assessing these cases because it provides a view of the roots and enables the examiner to envisage the path they will have to take to move into position. This case of transposition of canine and first premolar is a good example. (fig. 12). After explaining the risks of root resorption and the benefits of correction to the patient and his parents, we all agreed to treat this problem. The images show that the available space left some margin of maneuverability for the required orthodontic movement.

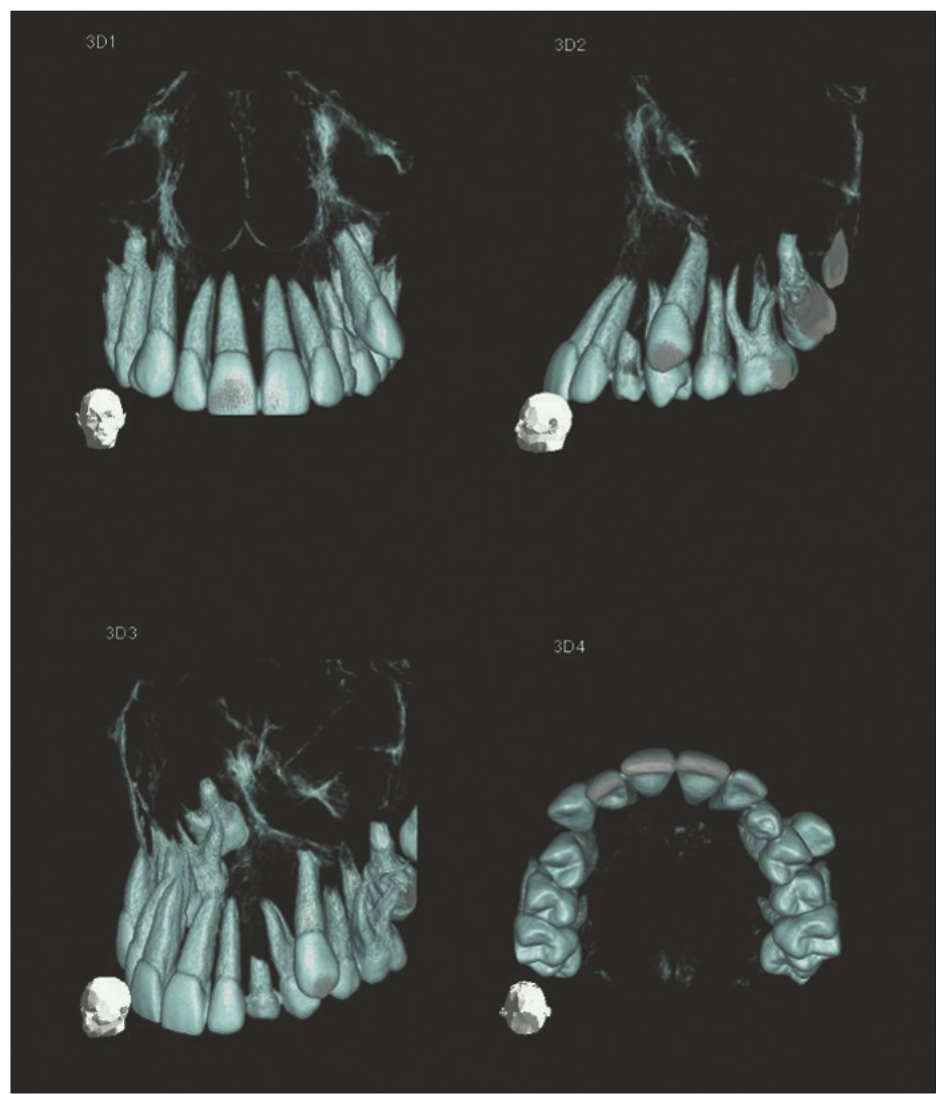

Figure 12

$3 D$ imaging is also highly useful in viewing the relationships of roots in cases of transposed teeth. These images (Pasquet and Cavezian) show transposition of the left maxillary canine and first premolar. $3 D$ reconstruction of the entire dentition, from all the sections gives a good view of the relationships of the roots of the teeth with each other and with neighbouring anatomical structures. Taken together with the details of the clinical examination they give the treating orthodontist enough information to decide whether correction of the transposition is indicated or contraindicated. 


\section{4 - CONCLUSION}

Scanner imaging can provide X-ray films that are invaluable in the diagnosis of impacted teeth, the position of roots of transposed teeth, or of teeth in complicated situations like those located on the edges of facial clefts, and of duplicated teeth. This type of imaging has become more accessible but it still requires the employment of bulky equipment and exposes patients to significant amounts of radiation. At present, digital cone beam computed tomography is an appropriate alternative for the orofacial sphere, emitting, as it does, far less radiation and providing even higher quality images. This diagnostic tool widely extends the range of information gathering that has traditionally been available in orthodontics $^{22}$ or implantology, And promises to be immensely useful to endodontists searching out foci of periapical infections. Pinpointing the indications 7,13 and the limitations of these supplementary examinations is essential, as specified in article R. 1333-56 of the Public Health Code which requires practitioners to make sure that no other technique of comparable efficacy but with "less risk" are available...

CBCT10 meets the need for providing accurate investigation of a wide range but demanding minimal irradiation, which optimises the risk-benefit ratio. We share the opinion of Cavézia ${ }^{5}$ who anticipates a bright future for this type of exploration.

\section{BIBLIOGRAPHY}

1. American Academy of Oral and Maxillofacial Radiology. Executive opinion statement on performing and interpreting diagnostic cone-beam computed tomographiy. Oral Surg Oral Med Oral Path Oral Radiol Endod 2008;106:561-62.

2. Angelopoulos $C$. Cone beam tomographic Imaging anatomy of the maxillofacial région. Dent Clin North Am 2008 Oct;52(4):731-52, vi.

3. Autorité de sureté Nucléaire. Présentation des principales dispositions réglementaires de radioprotection applicables en radiologie médicale et dentaire.

4. Cavezian R, Pasquet G. L'imagerie médicale en odontologie. Paris : Édition CdP, 2005.

5. Cavezian R, Pasquet G. Imagerie et orthopédiedento-faciale : évolution, présentet avenir. Orthod Fr 2008;79:3-12.

6. Cavezian R, Pasquet G, Batard J. Imagerie sectionnelle en odontostomatologie : de la tomographie au scanner RX et au cone beam. Réalités cliniques 2008;19(2):151-65.

7. Code de la Santé Publique. Guide des indications et des procédures des examens radiologiques en odontostomatologie. Paris : Dalloz, 2006.

8. Delsol L, Orti V, Chouvin M, Canal P. Canines et incisives maxillaires incluses: diagnostic et thérapeutique. EMC (Elsevier SAS, Paris) Odontologie : Orthopédie dentofaciale 23-492-A-11, 2006.

9. Foucart JM. La radioprotection en odontologie. Paris : Édition CdP, 2004.

10. Foucart JM, Felizardo R, Bourriau J, Bidange G. La tomographie volumique à faisceau conique (CBCT) : du mythe à la réalité. Clinic 2009;Oct;30:483-91. 
11. Garrett BJ, Caruso JM, Rungcharassaeng K, Farrage JR, Kim JS. Skeletal effects to the maxilla after maxillary expansion with cone-beam computed tomography. Eur J Radiol 2008; Jul:23.

12. Guiral H, Medina L, Cavezian R, Pasquet G. Localisation des canines incluses : mise au point. AOS 2009;245:63-70.

13. Has. Guide des indications et des procédures des examens radiologiques en odontostomatologie, 2006.

14. Hauret L, Hodez C. Nouveauté en radiologie dento-maxillofaciale : la tomographie volumétrique à faisceau conique. J Radiol 2009;90:604-17.

15. Horner K, Islam M, Flygare L, Tsiklakis K, Whaites E. Basic principles for use of dental cone beam computed tomography: consensus guidelines of the European Academy of Dental and Maxillofacial Radiology. Dentomaxillofac Radiol 2009 May;35(3):152-7.

16. Korbendau JM, Guyomard F. Chirurgie muco-gingivale chez l'enfant et l'adolescent. Paris : CdP, 1992:212.

17. Korbendau JM, Patti A. Le traitement orthodontique et chirurgical des dents incluses. Quintessence international, 2005. Réussir, 135 p.

18. Ludlow JB, Davies-Ludlow LE, Brooks SL, Howerton WB. Dosimetry of 3 CBCT devices for oral and maxillofacial radiology: CB MercurRay, NewTom 3G, and i-Cat. Dentomaxillofacial Radiology 2006;35:219-26.

19. Noble J, Hechter FJ, Karaiskos NE, Lekic N, Wiltshire XA. Future practice plans of orthodontic résidents in thr United States. Am J Orthod Dentofacial Orthop 2009 Mar;135(3):357-60.

20. Nrdstrom D. Radiographic exposure guidelines. Am J Orthod Dentofacial Orthop 2009 Mar;135 (3):272.

21. Rungcharassaeng K, Caruso J, Kan J, Kim J, Taylor G, Factors affecting buccal bone changes of maxillary posterior teeth after rapid maxillary expansion. Am $\mathrm{J}$ of Orthod Dentofacial Orthop 2007 Oct;132-4:428.e1-428.e8.

22. Treil J, Bracia J, Aïat Ameur A. Modélisation 3D du viscéro-crâne. Applications en orthodontie et clinique orthognatique. J Radiol 2009;90:634-41.

23. Walker L, Enciso R, Mah J. Three-dimensional localization of maxillary canines with cone-beam computed tomography. Am J Orthod Dentofacial Orthop 2005;128(4):418-23. 